\title{
Baddeleyite as a widespread and sensitive indicator of meteorite bombardment in planetary crusts
}

\author{
L.F. White ${ }^{1,2,3}$, J.R. Darling1 , D.E. Moser ${ }^{4}$, C. Cayron ${ }^{5}$, I. Barker ${ }^{2}$, J. Dunlop ${ }^{1}$, and \\ K.T. Tait ${ }^{2,3}$ \\ ${ }^{1}$ School of Earth and Environmental Sciences, University of Portsmouth, Portsmouth \\ PO1 3QL, UK \\ ${ }^{2}$ Department of Natural History, Royal Ontario Museum, 100 Queens Park, Toronto, \\ Ontario M5S 2C6, Canada \\ ${ }^{3}$ Deparment of Earth Sciences, University of Toronto, Toronto, Ontario M5S 3H7, \\ Canada \\ ${ }^{4}$ Department of Earth Sciences, University of Western Ontario, London N6A 5B7, \\ Canada \\ ${ }^{5}$ Laboratory of ThermoMechanical Metallurgy (LMTM), École Polytechnique Fédérale \\ de Lausanne (EPFL), Rue de la Maladière 71b,2000 Neuchâtel, Switzerland \\ *Email: 1white@rom.on.ca
}

\begin{abstract}
Constraining the timing and intensity of Solar System bombardment is critical to understanding planetary formation, evolution and habitability. However, the identification and dating of shock-metamorphic events in the mafic igneous lithologies that dominate planetary materials remains highly challenging, particularly at relatively modest shock pressures. The accessory mineral baddeleyite (monoclinic- $\mathrm{ZrO}_{2}$ ) is
\end{abstract}


abundant in these mafic crustal rocks, though the microstructural response of this mineral to shock loading is currently unconstrained. Here we show that baddeleyite yields a predictable sequence of microstructures in the shock pressure range of 5 to $\sim 20 \mathrm{GPa}$, based on analysis of mafic rocks collected along a well-constrained shock-pressure gradient in the crystalline bedrock of the Sudbury impact structure, Canada. Highresolution electron backscatter diffraction mapping of baddeleyite grains exposed to $<20$ GPa of shock loading reveals a range of microstructures, including complex orthogonally related crystalline subgrains, amorphous domains, and crystal plastic deformation. Evidence that the observed microstructures are controlled by the transition to, and subsequent reversion from, the high-pressure (experimentally constrained to $>5 \mathrm{GPa}$ ) orthorhombic- $\mathrm{ZrO}_{2}$ polymorph is provided by phase-heritage reconstruction using relationships between reverted monoclinic orientations. Our results demonstrate that baddeleyite is a sensitive shock indicator and barometer over low pressure ranges largely inaccessible with other minerals, augmenting ongoing studies, with other mafic minerals, into the intensity of inner Solar System bombardment.

\section{INTRODUCTION}

Constraining the extent and severity of shock metamorphism is critical when interpreting petrological and geochemical records of planetary evolution. Refractory, high-temperature accessory phases, such as zircon, have been shown to generate a range of diagnostic microstructural features during impact events (Moser et al., 2011); however, magmatic zircon occurs infrequently in mafic igneous rocks. While identified impacts into basaltic target rocks are rare on Earth, the prevalence of mafic to ultra-mafic 
lithologies within the inner Solar System means that constraining the response of these lithologies to shock metamorphism is important in understanding the formation and evolution of many planetary bodies. Existing shock barometers within these materials, such as planar deformation features in plagioclase (>18 GPa; Stöffler et al., 2018), will not form in moderately shocked materials and, once present, are susceptible to recrystallization. The accessory phase baddeleyite (monoclinic- $\mathrm{ZrO}_{2}$ ) readily crystallizes from mafic magmas, and occurs in a wide range of planetary materials (Herd et al., 2017). $\mathrm{ZrO}_{2}$ has a monoclinic space group $\left(\mathrm{P} 2_{1} / \mathrm{c}\right)$ at pressures below $\sim 5 \mathrm{GPa}$ and temperatures below $\sim 1400{ }^{\circ} \mathrm{C}$ (McCullough and Trueblood 1959), which defines the stability field of magmatic baddeleyite. When exposed to high-temperature conditions, distortion of this monoclinic structure occurs through a succession of phase transformations to tetragonal $\left(t-\mathrm{ZrO}_{2} ;>1400{ }^{\circ} \mathrm{C}\right.$ at ambient pressure $)$ and cubic $\left(c-\mathrm{ZrO}_{2}\right.$; $>2400{ }^{\circ} \mathrm{C}$ ) forms (Subbarao et al., 1974). High-pressure conditions (above $\sim 5 \mathrm{GPa}$ ) likewise promote a reconfiguration of the $\mathrm{ZrO}_{2}$ lattice via transformations to a series of orthorhombic structures with increasing pressure (o- $\mathrm{ZrO}_{2}$; Kudoh et al., 1986). Although these phases readily revert to the monoclinic structure at ambient conditions (Subbarao et al., 1974), their former existence can be inferred from unique crystallographic orientation relationships (ORs) between reverted monoclinic domains (Cayron et al., 2006, 2010; Timms et al., 2017). Here we describe the microstructural characteristics of baddeleyite grains within a range of unshocked to variably shocked doleritic dikes surrounding the Sudbury impact structure (Ontario, Canada). By highlighting a range of unique crystallographic features and correlating these with formation and reversion of metastable 
orthorhombic- $\mathrm{ZrO}_{2}$, we begin to establish the phase as an important tool in the identification and quantification of modestly shocked (>5 GPa) planetary materials.

\section{SAMPLES AND METHODOLOGY}

Baddeleyite-bearing samples of the $2473 \pm 16$ Ma Matachewan dike swarm (Heaman, 1997) were collected at varying distances (between $0.55 \mathrm{~km}$ and $180 \mathrm{~km}$ ) from the present surface expression of the Sudbury impact melt sheet, from dikes outcropping in both the Levack gneiss complex and the Cartier granitic batholith (Fig. 1). Samples are primarily doleritic in composition, though are variably overprinted by greenschist-facies metamorphism. Feldspar appears crystalline though cloudy, with no clear shock features. A zircon-bearing pre-impact granitic intrusion was also sampled adjacent to the dike nearest the melt sheet $(0.55 \mathrm{~km})$. Bulk shock pressure and temperature $(P-T)$ histories for these samples can be estimated through numerical modeling of the Sudbury impact (Ivanov, 2005), and by coupling the extensive reports of shock features in the surrounding target rocks with thermal modeling and waste heat calculations for the North Range (e.g., James et al., 1992).

Baddeleyite and zircon grains were located and imaged in situ using a combination of automated backscattered electron (BSE) and energy-dispersive X-ray spectroscopy (EDS) techniques. Micro- to nano-scale structural analysis of baddeleyite was conducted by high-resolution (>50 nm step size) electron backscatter diffraction (EBSD) following previously reported techniques (Darling et al., 2016), while phase reconstruction was conducted using the ARPGE software package (Cayron et al., 2006). Orthorhombic, tetragonal, and cubic structures of $\mathrm{ZrO}_{2}$ were not directly observed in any 
of the analyzed grains. Zircon grains were analyzed and indexed following previously reported conditions (Moser et al. 2011). Wild spike reduction was completed on all EBSD data sets, but no other form of raw data correction was conducted. Full details on instrument and analytical parameters, and the ARPGE reconstruction protocol, can be found in the GSA Data Repository ${ }^{1}$ and in Cayron et al. (2010).

\section{MICROSTRUCTURAL RESULTS}

EBSD maps can be used to quantitatively demonstrate the existence of a precursor high-symmetry phase that can be orthorhombic, tetragonal, or cubic. However, zirconia orientation relationships (ORs) are rarely strict; very often, the defining OR is actually composed of multiple ORs (see types 1,2,3, A,B,C of Cayron et al. [2006]), meaning a unique parent phase cannot always be unambiguously defined given the complex $P-T$ history of natural samples. However, this information can used in conjunction with independent qualifiers of $P-T$ history to greatly aid in interpreting the phase history of target baddeleyite grains.

\section{Unshocked Baddeleyite Microstructure}

Baddeleyite grains analyzed in unshocked Matachewan Dike sample MDS001 (sampled $\sim 180 \mathrm{~km}$ from the Sudbury impact melt sheet) yield high-quality electron backscatter patterns (EBSPs) and display simple twin planes $\left(180^{\circ} /<001>\right)$. An $\sim 18^{\circ}$ relationship can be observed between the twin domains in the $\{001\}$ pole figure, likely generated by a mirroring of the monoclinic $\beta$ angle $\left(80.5^{\circ}\right)$ about the simple twin interface; such twinning (along with $\{100\}$ and $\{110\}$ twinning) is well-described in 
unshocked baddeleyite grains (McCullough and Trueblood 1959). We interpret the observed crystallographic twin orientation to be indicative of undeformed primary baddeleyite grains. None of the unshocked crystals observed in this study $(n=7)$ display evidence of crystal plastic deformation, with cumulative crystal-lattice misorientations falling within the $\sim 0.5^{\circ}$ angular detection limit of the technique. These results provide a baseline of the structural characteristics of unshocked baddeleyite grains (Fig. 2A).

\section{Shocked Baddeleyite Microstructure}

Sample JD12SUD06 was collected from an outcrop $\sim 8 \mathrm{~km}$ (horizontal distance) from the lower contact of the melt sheet (falling between defined limits of shattercone and quartz planar deformation fabric [PDF] formation; Grieve et al. 2008), constraining the bulk shock pressures experienced by the sample to between $2 \mathrm{GPa}$ and $10 \mathrm{GPa}$, respectively (Langenhorst, 1994; Grieve et al., 2008). Grains are relatively undeformed, preserving igneous twin relationships $\left(180^{\circ} /<001>\right.$; $18^{\circ}$ misorientation in $\left.\{001\}\right)$ and displaying internal crystal-lattice misorientations on the order of $<2^{\circ}$. Within two grains, crystalline subgrains contain up to 11 uniquely orientated subdomains. One composite grain represents two baddeleyite crystals intercepting at roughly $\sim 90^{\circ}$, with one grain (I) displaying simple twinning $\left(180^{\circ} /<001>, 18^{\circ} /\{001\}\right)$ and a second (II) containing an abundance of subgrain domains segregated by high-angle $\left(>10^{\circ}\right)$ boundaries (Fig. 2B). While all measured monoclinic orientations can be associated with a single parent $\mathrm{ZrO}_{2}$ phase, this phase heritage is constrained by the ORs within grain II. ARPGE reconstruction of grain II constrains the potential parent- $\mathrm{ZrO}_{2}$ phase to either the tetragonal or orthorhombic structures. Grain II displays an absence of known magmatic 
baddeleyite twin laws, including $180^{\circ} /<001>$ twins observed in unshocked sections of the Matachewan dike swarm. Relative misorientation peaks at $0^{\circ}, 90^{\circ}$, and $180^{\circ}$, coupled with an absence of $120^{\circ}$ misorientations in grain II, are further evidence of a tetragonal or orthorhombic parent (see the Data Repository).

A total of seven baddeleyite grains have been investigated in sample JD12SUD03, sampled $\sim 3 \mathrm{~km}$ from the melt sheet (falling within the North Range quartz PDF limit and constraining shock pressures to >10 GPa; Langenhorst 1994; Grieve et al. 2008). All grains display complex, irregular, micrometer- to submicrometer-scale baddeleyite domains divided by subgrain boundaries that yield weaker EBSPs (i.e., Fig. 2C). Crystalline subdomains yield distinct, loosely clustered, orthogonally related groups of crystallographic orientations in $\langle 100\rangle,\langle 010\rangle$, and $\langle 001\rangle$ pole figures. Three orientations are observed in all pole directions, which could, in theory, be associated with a single cubic- $\mathrm{ZrO}_{2}$ parent. However, multiple ORs generated by orthorhombic $\rightarrow$ monoclinic reversion can also yield the observed relationships, and, as such, the parent phase cannot be accurately constrained from the ORs alone. Misorientation peaks can be observed at $0^{\circ}, 90^{\circ}, 120^{\circ}$, and $180^{\circ}$ (see the Data Repository).

Seven grains within the most-highly shocked sample (collected $\sim 0.55 \mathrm{~km}$ from the melt sheet) are composed of pervasively twinned, interlocking baddeleyite domains forming a complex crystalline mosaic (Fig. 2D). Two principal crystallographic orientations are prevalent within the grain, related by a $90^{\circ}$ operator around $\langle 401\rangle$. Both subdomains host narrow $(<250 \mathrm{~nm})$, discontinuous, $180^{\circ} /<101>$ lamella that highlight tight groupings of orthogonally related crystallographic orientations in $\langle 100\rangle,\langle 010\rangle$, and $<001>$ pole figures. These internal structures terminate at the boundary of the 
associated host domain. The predominant crystallographic domain displays extensive $\left(<9^{\circ}\right)$ internal deformation, while smaller subgrains are limited to $\sim 3^{\circ}$ of deformation. ARPGE reconstruction of the grain reveals that measured (010) orientations are congruent with only two $\{100\}$ cubic planes, ruling out a cubic- $\mathrm{ZrO}_{2}$ parent. Two unique ORs can be used to trace a tetragonal parent phase, though multiple orthorhombic $\rightarrow$ monoclinic ORs would also overlap with this reconstruction, suggesting either a tetragonal or orthorhombic parent for the grain. Preservation of primary magmatic baddeleyite, as inferred from subdomains yielding $\mathrm{U}-\mathrm{Pb}$ ages congruent with the crystallization of the Matachewan dike swarm (White et al., 2017a), further complicate phase reconstruction for these grains.

\section{Shocked Zircon Microstructure}

Granitoid JD12SUD15a was sampled adjacent to JD12SUD14. EBSD analysis was conducted on a single large zircon grain that displays a series of crystallographic features, including crystal plastic deformation $\left(<8^{\circ}\right.$ misorientation $)$ and multiple $\{112\}$ microtwin lamella $\left(350-400 \mathrm{~nm}\right.$ width) rotated $65^{\circ}$ about $\langle 110\rangle$. A small number of micrometer-scale subgrains $(<15 \mu \mathrm{m})$ are recognized by low-angle $\left(<6^{\circ}\right)$ grain boundaries to the host zircon and are principally observed in association with identified microtwins. 


\section{DISCUSSION}

\section{Pressure-Temperature Constraints on Baddeleyite Phase Heritage}

Microstructural analysis of impact-proximal baddeleyite grains reveals a complex mosaic of orthogonally twinned, interlocking $\mathrm{ZrO}_{2}$ subgrains. Importantly, orthogonal relationships cannot be generated by twinning of the monoclinic structure alone, instead requiring the formation and reversion of high-symmetry $\mathrm{ZrO}_{2}$ polymorphs (i.e., Cayron et al., 2006). Overlapping ORs from a precursor cubic, tetragonal, or orthorhombic parent, and, in particular, the preservation of some magmatic monoclinic domains, hinder the accurate reconstruction of a unique parent structure in these complex monoclinic data sets. However, orthogonal relationships quantitatively prove the former existence of a high-symmetry (cubic, tetragonal, orthorhombic) parent phase based on the ARPGE reconstruction conducted during this study, though additional $P-T$ constraints are required to further refine the nature of the parent phase. Here, the most impact-proximal sample (JD12SUD14) would have undergone a maximum of $\sim 950^{\circ} \mathrm{C}$ of annealing during contact metamorphism with the impact melt sheet (James et al., 1992; Ivanov, 2005) and neglible $\left(\sim 55^{\circ} \mathrm{C}\right)$ waste heat generation during shock loading (see the Data Repository). These modeling predictions are supported by recent $\mathrm{Zr} / \mathrm{Hf}$ work that has demonstrated that only basalt in exceptionally close proximity $(<0.25 \mathrm{~km})$ to the impact melt sheet would undergo Zr-Hf decoupling attributed to partial melting (Jørgensen et al., 2018). As a result, even our most proximal sample $(0.55 \mathrm{~km})$ has theoretically not been exposed to the high-temperature conditions required to induce the formation of the tertragonal- $\mathrm{ZrO}_{2}$ phase $\left(>1400{ }^{\circ} \mathrm{C}\right)$. However, the regional occurrence of quartz PDFs (>10 GPa) and presence of zircon microtwins in adjacent felsic rocks (sample JD12SUD15a) reveal that 
pressures of $\sim 20 \mathrm{GPa}$ were experienced by the sample (Timms et al., 2017). Isotopic dating of baddeleyite grains within sample JD12SUD14 by atom probe tomography reveals the presence of discrete, nanoscale, dike-crystallization (ca. $2.47 \mathrm{Ga}$ ) and impact aged subdomains (1.85 Ga; White et al., 2017a). This observation acts to strengthen the correlation between the observed microstructure and the ca. 1.85 Ga impact event (Krogh et al., 1984), reinforcing the interpretation of only partial transformation of the grain to a high-symmetry polymorph. It also places further temperature constraints on the grains, which must have been exposed to temperatures below $\sim 1000{ }^{\circ} \mathrm{C}$ given the closure temperature of micrometer-scale $\mathrm{Pb}$ diffusion in baddeleyite (Heaman and LeCheminant 1993). These $P-T$ constraints strongly suggest that the partial formation and reversion of the high-pressure orthorhombic phase was responsible for the range of microstructural phenomena observed here.

\section{Utility of Baddeleyite as a Shock Indicator and Barometer}

The preservation of crystallization-aged subdomains within the most highly shocked baddeleyite population (White et al., 2017a) suggests that a subset of the magmatic baddeleyite did not transition to the orthorhombic structure, preserving crystallization age $\mathrm{U}-\mathrm{Th}-\mathrm{Pb}$ systematics and, presumably, a primary crystallographic orientation independent of those domains associated with phase heritage. These domains are also incorporated into the reconstruction protocol, theoretically overestimating the symmetry of parent phases. As a result, phase reconstruction in complex shocked baddeleyite must be supplemented by careful examination of the nature of grain boundaries and of the $h k l$ pole figures themselves. In this way, important criteria can be 
used to distinguish grains reverted from an orthorombic- $\mathrm{ZrO}_{2}$ parent (those required for impact identification) from primary igneous baddeleyite and grains reverted from a parent cubic- $\mathrm{ZrO}_{2}$ structure. Principally, such grains can be identified by (1) irregular grain boundaries isolating internal reversion domains, (2) three discrete clusters of orthogonally related crystallographic orientations in $\{100\}$ and $\{001\}$ pole figures and two clusters in $\{010\}$, and (3) occurrence of systematically distributed $\left(\sim 20^{\circ}\right)$ cross shapes within a single orientation cluster.

Although trace element variations in mineral chemistry can subtly alter the $P-T$ conditions required to induce the $m-\mathrm{ZrO}_{2}$ to $o-\mathrm{ZrO}_{2}$ transition (Hannink et al., 2000), the orthorhombic structure has never been induced below 5 GPa (Kudoh et al., 1986). Importantly, the orthorhombic transition can be partial upto pressures of $\sim 80 \mathrm{GPa}$ due to the anisotropic elastic properties of zirconia (Kudoh et al., 1986). This suggests that even in highly shocked planetary samples, it is unlikely the whole baddeleyite grain will transform, instead preserving primary orientation and age data in at least some subdomains (i.e., White et al., 2017a). The only known potential for overprinting of microstructure within shocked baddeleyite comes from the reaction with free-silica during endogenic crustal metamorphism or melting (Heaman and LeCheminant 1993). However, the shock microstructures are retained within preserved baddeleyite domains in the partially overprinted Matachewan dike samples examined here. Coupled with the natural toughening of $\mathrm{ZrO}_{2}$ through structural phase changes and grain-size reduction (and microstructure retained through their retrogression; Hannink et al., 2000), unique impact-generated structures such as those outlined here will likely be retained through extensive reworking and overprinting events. As such, baddeleyite appears to be a 
particularly powerful indicator and barometer of impact deformation, with the ability to augment interpretation of shock history in a low-pressure range as well as within more mafic planetary crusts.

\section{ACKNOWLEDGMENTS}

White is supported by a Hatch postdoctoral fellowship. Darling acknowledges funding supplied by the Geological Society of London in the form of the Elspeth Matthews award (2013), supporting collection of the Matachewan Dike samples. We thank Larry Heaman for supplying sample MDS001, and Geoff Long for assistance with thin section preparation and colloidal silica polishing at the University of Portsmouth, UK. We thank A. Cavosie and T. Erickson for constructive and insightful reviews, which greatly improved this manuscript, and J. Schmitt for editorial handling.

\section{REFERENCES CITED}

Cayron, C., Artaud, B., and Briottet, L., 2006, Reconstruction of parent grains from EBSD data: Materials Characterization, v. 57, p. 386-401, https://doi.org/10.1016/j.matchar.2006.03.008.

Cayron, C., Douillard, T., Sibil, A., Fantozzi, G., and Sao-Jao, S., 2010, Reconstruction of the cubic and tetragonal parent grains from electron backscatter diffraction maps of monoclinic zirconia: Journal of the American Ceramic Society, v. 93, p. 25412544, https://doi.org/10.1111/j.1551-2916.2010.03894.x.

Darling, J.R., Moser, D.E., Barker, I.R., Tait, K.T., Chamberlain, K.R., Schmitt, A.K., and Hyde, B.C., 2016, Variable microstructural response of baddeleyite to shock 
metamorphism in young basaltic shergottite NWA 5298 and improved U-Pb dating of Solar System events: Earth and Planetary Science Letters, v. 444, p. 1-12, https://doi.org/10.1016/j.eps1.2016.03.032.

Grieve, R.A.F., Reimold, U., Morgan, J.V., Riller, U., and Pilkington, M., 2008, Observations and interpretations at Vredefort, Sudbury, and Chicxulub; Towards an empirical model of terrestrial impact basin formation: Meteoritics \& Planetary Science, v. 43, p. 855-882, https://doi.org/10.1111/j.1945-5100.2008.tb01086.x. Hannink, R.H.J., Kelly, P.M., and Muddle, B.C., 2000, Transformation toughening in zirconia-containing ceramics: Journal of the American Ceramic Society, v. 83, p. 461-487, https://doi.org/10.1111/j.1151-2916.2000.tb01221.x.

Heaman, L.M., 1997, Global mafic volcanism at 2.4 Ga: Remnants of an ancient large igneous province?: Geology, v. 25, p. 299-302, https://doi.org/10.1130/00917613(1997)025<0299:GMMAGR>2.3.CO;2.

Heaman, L.M., and LeCheminant, A.N., 1993, Paragenesis and U-Pb systematics of baddeleyite $\left(\mathrm{ZrO}_{2}\right)$ : Chemical Geology, v. 110, p. 95-126, https://doi.org/10.1016/0009-2541(93)90249-I.

Herd, C.D.K., Moser, D.E., Tait, K., Darling, J.R., Shaulis, B.J.M., and McCoy, T.J., 2017. Crystallization of baddeleyite in basaltic rocks from Mars, and comparisons with the Earth, Moon and Vesta, in Moser, D., et al., eds., Microstructural Geochronology: Planetary Records Down to Atom Scale: Hoboken, New Jersey, John Wiley \& Sons, Inc., https://doi.org/10.1002/9781119227250.ch6.

Ivanov, B.A., 2005, Numerical modeling of the largest terrestrial meteorite craters: Solar System Research, v. 39, p. 381-409, https://doi.org/10.1007/s11208-005-0051-0. 
James, R.S., Sweeny, J.M., and Peredery, W.V., 1992, Thermobarometry of the Levack gneisses-Footwall rocks to the Sudbury Igneous Complex (SIC): Lithoprobe Report, v. 25, p. 179-182.

Jørgensen, T.R.C., Tinkham, D.K., Lesher, C.M., and Petrus, J.A., 2018, Decoupling of $\mathrm{Zr}-\mathrm{Hf}$ during contact metamorphic anatexis of metabasalts and timing of zircon growth, Sudbury, Canada: Geology, v. 46, p. 159-162, https://doi.org/10.1130/G39590.1.

Krogh, T.E., Davis, D.W., and Corfu, F., 1984, Precise U-Pb zircon and baddeleyite ages for the Sudbury area, in Pye, E.G., et al., eds., The Geology and Ore Deposits of the Sudbury Structure: Ontario Geological Survey Special Volume 1, p. 431-446.

Kudoh, Y., Takeda, H., and Arashi, H., 1986, In situ determination of crystal structure for high pressure phase of $\mathrm{ZrO}_{2}$ using a diamond anvil and single crystal $\mathrm{X}$-ray diffraction method: Physics and Chemistry of Minerals, v. 13, p. 233-237, https://doi.org/10.1007/BF00308274.

Langenhorst, F., 1994, Shock experiments on pre-heated $\alpha$ - and $\beta$-quartz: II. X-ray and TEM investigations: Earth and Planetary Science Letters, v. 128, p. 683-698, https://doi.org/10.1016/0012-821X(94)90179-1.

McCullough, J.D., and Trueblood, K.N., 1959, The crystal structure of baddeleyite (monoclinic $\mathrm{ZrO}_{2}$ ): Acta Crystallographica, v. 12, p. 507-511, https://doi.org/10.1107/S0365110X59001530.

Moser, D.E., Cupelli, C.L., Barker, I.R., Flowers, R.M., Bowman, J.R., Wooden, J., and Hart, J.R., 2011, New zircon shock phenomena and their use for dating and reconstruction of large impact structures revealed by electron nanobeam (EBSD, CL, 
EDS) and isotopic U-Pb and (U-Th)/He analysis of the Vredefort dome: Canadian Journal of Earth Sciences, v. 48, p. 117-139, https://doi.org/10.1139/E11-011.

Stöffler, D., Hamann, C., and Metzler, K., 2018, Shock metamorphism of planetary silicate rocks and sediments: Proposal for an updated classification system: Meteoritics \& Planetary Science, v. 53, p. 5-49, https://doi.org/10.1111/maps.12912. Subbarao, E.C., Maiti, H.S., and Srivastava, K.K., 1974, Martensitic Transformation in Zirconia [a]: Physica Status Solidi, v. 21, p. 9-40, https://doi.org/10.1002/pssa.2210210102.

Timms, N.E., Erickson, T.M., Pearce, M.A., Cavosie, A.J., Schmieder, M., Tohver, E., Reddy, S.M., Zanetti, M.R., Nemchin, A.A., and Wittmann, A., 2017, A pressuretemperature phase diagram for zircon at extreme conditions: Earth-Science Reviews, v. 165, p. 185-202, https://doi.org/10.1016/j.earscirev.2016.12.008.

White, L.F., Darling, J.R., Moser, D.E., Reinhard, D., Prosa, A., Bullen, T.J., Olson, D., Larson, D., Lawrence, D.J., and Martin, I., 2017a, Atomic-scale age resolution of planetary events: Nature Communications, v. 8, p. 15597, https://doi.org/10.1038/ncomms15597. 


\section{FIGURE CAPTIONS}

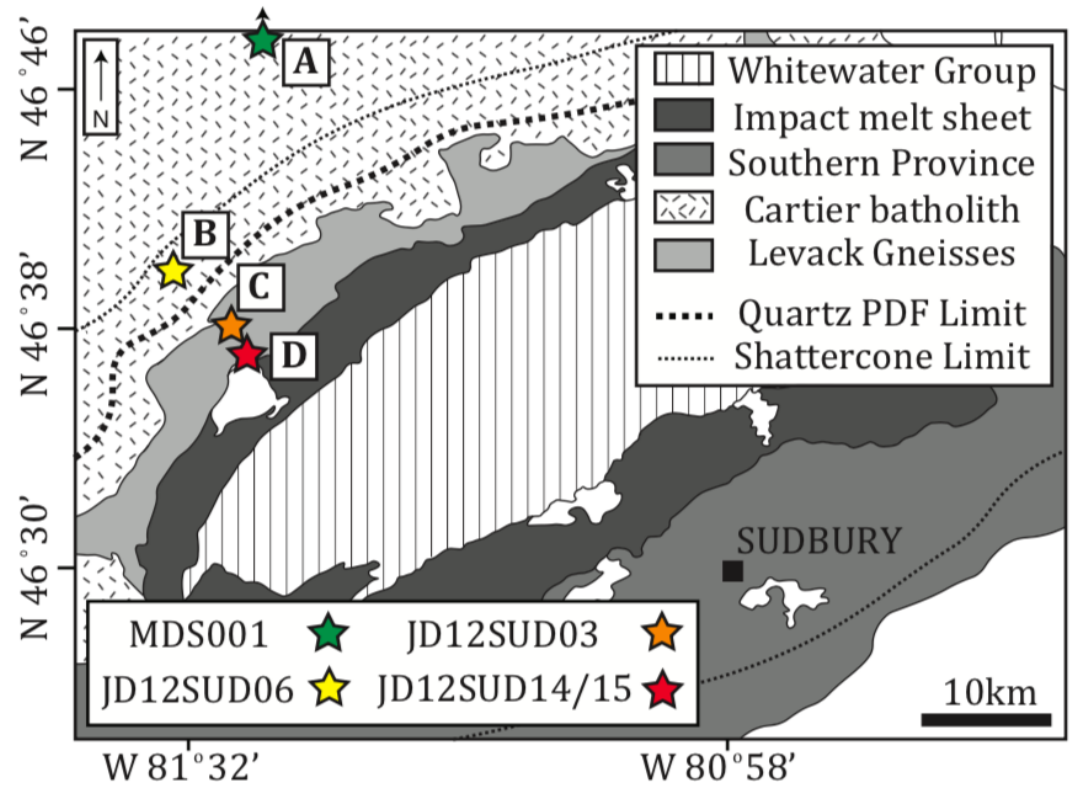

Figure 1. Schematic geological map of the Sudbury impact structure highlighting sample localities of variably shocked $\mathrm{ZrO}_{2}$-bearing material. Three baddeleyite-bearing samples of the Matachewan dike swarm (JD12SUD14, JD12SUD03, and JD12SUD06) form a roughly linear transect radiating outward from the northwestern extent of the Sudbury impact melt sheet, while sample MDS001 provides an unshocked sample for comparison. Sample JD12SUD15a represents a zircon-bearing felsic intrusion within the Levack gneisses sampled for comparison. PDF-planar deformation features. 


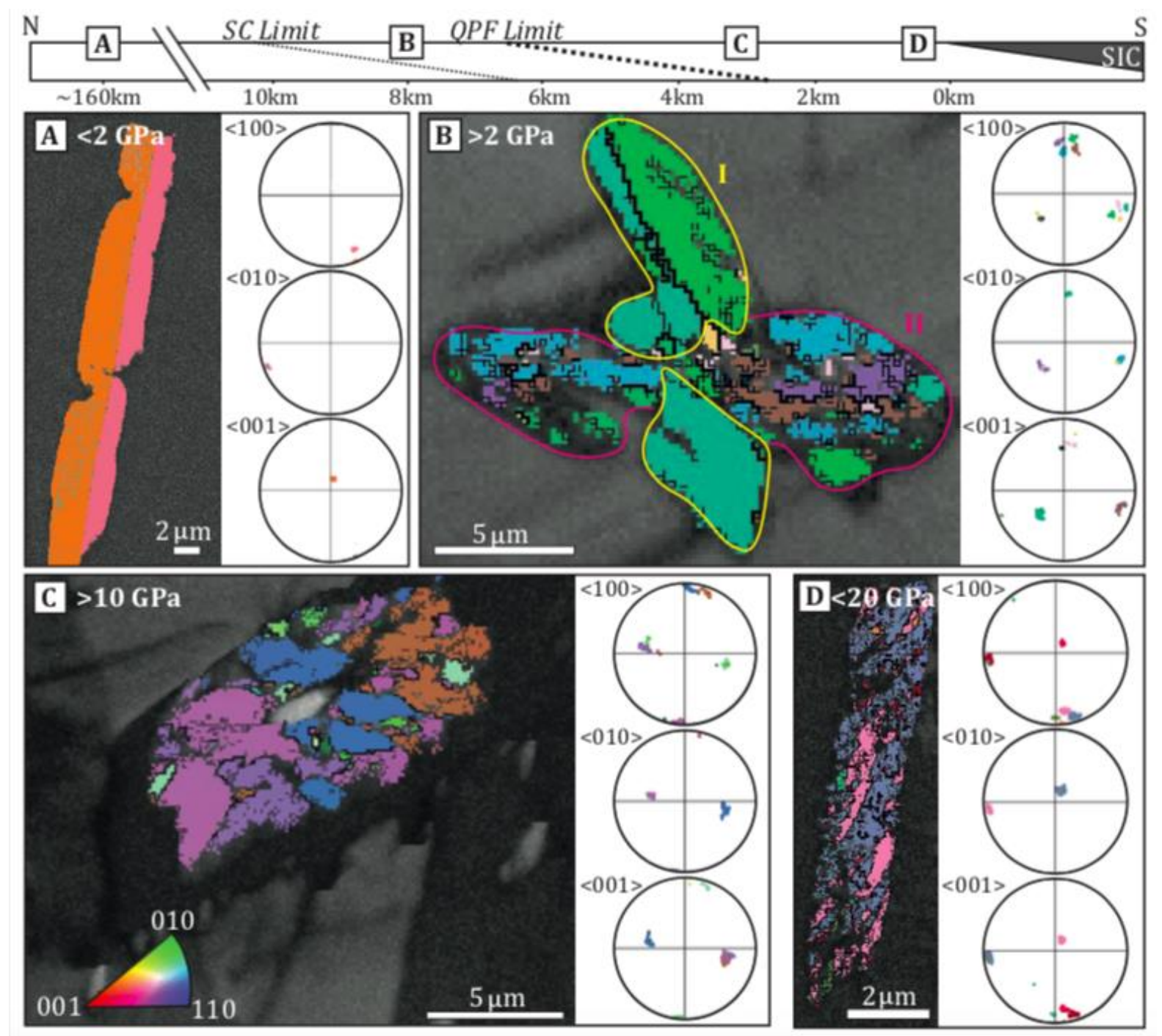

Figure 2. Electron backscatter diffraction (EBSD) microstructural data for baddeleyite grains collected across a linear transect north of the Sudbury impact structure. Presented data sets were collected at $<100 \mathrm{~nm}$ step size. All Euler maps are presented for grains within samples MDS001 (A), JD12SUD14 (B), JD12SUD06 (C), and JD12SUD14 (D) with $\angle 1^{\circ}$ (thin black lines) and $<10^{\circ}$ (thick gray lines) grain boundaries highlighted for the three shock-deformed samples (B-D). Subgrains I and II are highlighted in composite grain (B) for reference. This reveals the increasing nanostructural complexity of grains with increasing proximity to the Sudbury impact melt sheet, and evidences the loss of 
straight high-angle boundaries separating igneous twin domains. For reference, $\langle 100\rangle$, $<010>$, and $<001>$ pole figures are included for these data sets, highlighting the prevalence of orthogonally related crystallographic orientations in all shocked baddeleyite. SC—shattercone; QPF_ quartz planar features; SIC — Sudbury igenous complex.

${ }^{1}$ GSA Data Repository item 2018xxx, supplementary text and images for the samples, waste heat calcuations and phase reconstruction protocol, is available online at http://www.geosociety.org/datarepository/2018/, or on request from editing@geosociety.org. 